\title{
Aspartate Aminotransferase (AST) is a good Predictor of NAFLD Activity Score (NAS) for Diagnosing Non- alcoholic Steatohepatitis (NASH)
}

\author{
Alam SMN ${ }^{1}$, ${ }^{*}$ Das $\mathrm{DC}^{2}$, Alam S3, Mohsena $\mathrm{M}^{4}$, Mahtab MA ${ }^{5}$
}

\begin{abstract}
Nonalcoholic fatty liver disease (NAFLD) is a metabolic disorder characterized by excessive triglyceride accumulation in hepatocytes. NAFLD has a multifactorial etiology and a combination of environmental, genetic and metabolic factors play a role in the development of advanced disease. NAFLD consists of a wide spectrum of conditions, ranging from simple steatosis to nonalcoholic steatohepatitis (NASH) which can progress to cirrhosis and hepatocellular carcinoma (HCC). Despite the high prevalence and severity of hepatic illness, NAFLD remains underdiagnosed, because of few symptoms, lack of accurate laboratory markers. The accurate diagnosis of $N A S H$ remains dependent on specific histological parameters in liver biopsy. Although liver biopsy remains the 'gold standard', there are practical limitations, including costs and risks. There is an increasing requirement for simple, less invasive, highly accurate and affordable screening tools. Aspartate aminotransferase (AST) has been proposed as a noninvasive and available marker for assessment of NASH. A hospital based observational study was carried out for a period of two years in the Department of Hepatology, Bangabandhu Sheikh Mujib Medical University, Dhaka, Bangladesh. Data were analyzed by SPSS version 16. Qualitative and quantitative data were analyzed by Chi-square test and
\end{abstract}

1. Dr. Sheikh Mohammad Noor-E-Alam, Assistant Professor, Department of Hepatology, Bangabandhu Sheikh Mujib Medical University (BSMMU), Dhaka.

2. *Dr. Dulal Chandra Das, Medical Officer, Department of Hepatology, (BSMMU), Dhaka. Phone: 01711-786929, E-mail: dulaldas36@ gmail.com.

3. Dr. Md. Shahinul Alam, Associate Professor, Department of Hepatology, BSMMU, Dhaka.

4. Dr. Masuda Mohsena, Professor, Department of Community Medicine, Ibrahim Medical College, Dhaka.

5. Dr. Mamun Al Mahtab, Professor and Chairman, Department of Hepatology, BSMMU, Dhaka.

*For correspondence student's t-test respectively. Fifty (50) patients were analysed. Twenty five were NASH and twenty five were non-NASH. AST in NASH group were $55.2 \pm 30.1 \mathrm{IU} / \mathrm{L}$ and in

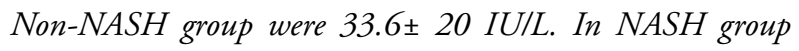
significantly higher percentage of raised AST had NASH compared with normal AST (68\% vs.32\%). There was significant difference in the NAFLD activity score for diagnosing NASH between elevated and normal AST (P value 0.004). Higher AST values correlated with higher specificity. By multivariate analysis AST were found to be significant. Thus Aspartate aminotransferase (AST) is a good predictor for diagnosing non- alcoholic steatohepatitis (NASH).

Keywords: Nonalcoholic fatty liver disease (NAFLD), Aspartate aminotransferase (AST), NAFLD activity score (NAS), Non-alcoholic Steatohepatitis (NASH).

\section{INTRODUCTION}

Nonalcoholic fatty liver disease (NAFLD) is a metabolic disorder characterized by excessive triglyceride accumulation in hepatocytes. ${ }^{1}$ NAFLD has a multifactorial etiology and a combination of environmental, genetic and metabolic factors play a role in the development of advanced disease. NAFLD is an acquired metabolic stress-induced liver disease associated with insulin resistance (IR) and genetic susceptibility, sharing histological similarities with alcoholic liver disease (ALD) in the absence of substantial alcohol consumption or other causes of liver disease. ${ }^{2}$ Two broad types are recognized-simple steatosis is typically stable while non-alcoholic steatohepatitis (NASH) is characterized by significant cell injury and the potential for progression to cirrhosis. ${ }^{3}$ NAFLD consists of a wide spectrum of conditions, ranging from simple steatosis to nonalcoholic steatohepatitis (NASH) which can progress to cirrhosis and hepatocellular carcinoma (HCC). ${ }^{4}$ Fatty liver may be diagnosed if liver echogenicity exceeds that of renal cortex and spleen and there is attenuation of the ultrasound wave, loss of definition of the diaphragm, 
and poor delineation of the intrahepatic architecture. However this finding is not specific and cannot be used to diagnose NASH. Its sensitivity range from $60-100 \%$ and its specificity from $77-95 \%$ in detecting fatty infiltration of the liver. ${ }^{5}$ A complete diagnosis of fatty liver disease ideally should define the histology, including the stage and grade of the disease as well as its etiology.

ALT is a marker of hepatic steatosis or hepatitis ${ }^{6}$ and NASH has been associated with slight elevation of liver enzymes. ${ }^{7}$ Patients typically present with asymptomatic serum aminotransferase elevations of 2-3 times the normal. ${ }^{8}$ This was also explored by Pulzi et al $2011^{9}$, where majority had mild elevation but less than 5 times upper normal limit and exists in all degree of NAFLD. But Alam et al 2013 showed serum alanine aminotransferase levels were not able to predict NASH. ${ }^{10}$

The AST/ALT ratio is approximately 0.8 in normal subjects. The AST is greater than the ALT in alcoholic hepatitis and a ratio greater than 2:1 is highly suggestive of this disorder. A ratio >1.0 may also suggest the presence of cirrhosis in patients with chronic viral hepatitis. ${ }^{11}$

NASH has been associated with slight elevation of liver enzymes mostly ALT and Gamma-glutamyl transferase (GGT) . ${ }^{7}$ Excess deposition of fat in the liver is associated with an elevated serum GGT and insulin resistance. ${ }^{12} \mathrm{An}$ increased GGT level is a risk factor for advanced fibrosis in NAFLD ${ }^{13}$ and with weight loss, a decrease in GGT activity is predictive of improved lobular inflammation and fibrosis of liver.

AST is a hepatic transaminase that plays a role in diagnosis of steatohepatitis. Up to $3.6 \%$ of people in the United States have asymptomatic increase in AST. ${ }^{14}$ In Asian studies, AST is considered as an independent marker for severity of hepatic fibrosis if it is at least twice as much as the maximum normal value. ${ }^{15}$

Liver biopsy remains the 'gold standard'for the diagnosis of $\mathrm{NASH}$, which allows us to differentiate simple steatosis from NASH. ${ }^{16}$ There are practical limitations, including costs and risk. Importantly longer cores are needed for accurate fibrosis staging. ${ }^{16}$

The aspartate aminotransferase (AST) has been proposed as a noninvasive and available marker for assessment of NASH.

\section{MATERIAL AND METHODS}

It was a hospital based observational study. The study was carried out for a period of 2 years in Department of Hepatology, Bangabandhu Sheikh Mujib Medical University (BSMMU), Dhaka, Bangladesh. Patients of NAFLD attending at Hepatology department were selected as study population. We took fifty NAFLD patients for biochemical parameters, liver biopsy and NAS score evaluation in considering the exclusion and inclusion criteria. NAS score was constructed according to Kleiner et al. (2005) with steatosis (0-3), lobular inflammation (0-3), hepatocellular ballooning (0-2), and a separate fibrosis staging $(0-4)$. The proposed NAS was the sum of steatosis, lobular inflammation, and hepatocellular ballooning. NAS is a strong scoring system. NAS of greater than or equal to 5 correlated with diagnosing of NASH and biopsy with scoring of 1 to 4 were diagnosed as NNFL (Non-NASH fatty liver). Patient's inclusion criteria were ultrasonographical evidence of fatty liver and patients from 18 to 60 years. Exclusion criteria were significant alcohol intake, viral hepatitis (HBV, HCV), Wilson's disease, autoimmune liver diseases, hereditary haemochromatosis, primary biliary cirrhosis, cirrhosis of liver, pregnancy, co-morbid conditions (COPD, CRF, cardiac failure), hypothyroidism, consumption of drugs causing fatty change in liver (steroid, oral contraceptive pill, tamoxifen, amiodarone, diltiagem, protease inhibitor). In AASLD Practice guideline 2018, significant alcohol consumption be defined as $>21$ standard drinks per week in men and $>14$ standard drinks per week in women over 2 years period preceding baseline liver histology. Liver biopsy was done in indoor of department of Hepatology, BSMMU by Trucut liver biospy needle $14 \mathrm{~F} 15 \mathrm{~cm}$. Tissue processed in Department of Pathology, BSMMU by standard protocol in automatic tissue processor (BAVIMED 2050, BAVIMED laborgeneratebau $\mathrm{GmBH}$, Birkeau, Germamy). Processed tissue than properly embedded on melted paraffin for making blocks and sections. The sections were stained with haematoxylin and eosin for microscopic examination. Histology report was done by Professor Mohammad Kamal, Chairman, Department of Pathology, BSMMU.

After receiving liver biopsy report they were grouped as $\mathrm{NASH}$ and Non-NASH. Consecutive $25 \mathrm{NASH}$ patient and 25 Non-NASH patient confirmed by liver biopsy were included in this study. All data were presented as mean \pm SD \& analyzed by SPSS (version 16). Qualitative data were analyzed by Chi-square test $\&$ quantitative data 
were analyzed by student's t-test. Performance of the test were assessed by sensitivity and specificity test. Statistically significant result were considered when $\mathrm{p}$ value $<0.05$.

\section{Ethical consideration}

Ethical clearance for the study was taken from the Institutional Review Board of BSMMU prior to the commencement of this study.

\section{RESULTS}

Fifty (50) patients were analysed. Twenty five were NASH and twenty five were Non- NASH. Overall, twenty eight (56\%) had normal AST. AST in NASH group were $55.2 \pm$ $30.1 \mathrm{IU} / \mathrm{L}$ and in Non-NASH group were 33.6 $\pm 20 \mathrm{IU} / \mathrm{L}$.

Table- 1: Distribution of the study patients by baseline characteristics $(\mathbf{n}=50)$

\begin{tabular}{|l|c|c|}
\hline Variables & Mean \pm SD & Min-Max \\
\hline Age (years) & $40.8 \pm 9.2$ & $25.0-60.0$ \\
\hline Weight (kg) & $64.5 \pm 9.2$ & $45.0-90.0$ \\
\hline Height (cm) & $158.4 \pm 8.6$ & $145.0-182.0$ \\
\hline BMI (kg/m ${ }^{2}$ ) & $25.7 \pm 4.0$ & $18.2-36.5$ \\
\hline Waist circumference (cm) & $95.9 \pm 9.5$ & $76.0-122.0$ \\
\hline $\begin{array}{l}\text { Systolic blood pressure } \\
\text { (mm of Hg) }\end{array}$ & $129.2 \pm 14.6$ & $100.0-160.0$ \\
\hline $\begin{array}{l}\text { Diastolic blood pressure } \\
\text { (mm of Hg) }\end{array}$ & $80.6 \pm 7.0$ & $70.0-100.0$ \\
\hline Platelet count (-x10 $/ \mathrm{L})$ & $315.4 \pm 69.6$ & $130.0-500.0$ \\
\hline $\begin{array}{l}\text { Fasting blood sugar } \\
\text { (mmol/L) }\end{array}$ & $6.2 \pm 2.6$ & $3.7-15.3$ \\
\hline 2HABF (mmol/L) & $9.5 \pm 4.4$ & $5.1-24.7$ \\
\hline Total cholesterol (mg/dl) & $205.0 \pm 44.8$ & $118.0-329.0$ \\
\hline LDL (mg/dl) & $122.8 \pm 39.2$ & $42.0-212.0$ \\
\hline HDL (mg/dl) & $38.7 \pm 9.3$ & $21.0-63.0$ \\
\hline TG (mg/dl) & $215.9 \pm 107.4$ & $58.0-441.0$ \\
\hline AST (U/L) & $44.4 \pm 28.2$ & $19.0-124.0$ \\
\hline ALT (U/L) & $76.2 \pm 47.4$ & $19.0-259.0$ \\
\hline AST/ALT & $0.6 \pm 0.2$ & $0.3-1.5$ \\
\hline HOMA-IR & $2.4 \pm 1.7$ & $0.4-8.5$ \\
\hline GGT (U/L) & $61.7 \pm 41.4$ & $12.0-209.0$ \\
\hline Serum ferritin (ụgm/L) & $121.4 \pm 101.6$ & $14.2-573.2$ \\
\hline
\end{tabular}

Table-II: Clinical and laboratory characteristics of study patients in two group $(n=50)$

\begin{tabular}{|l|c|c|c|}
\hline Variables & $\begin{array}{c}\text { NASH } \\
(\mathrm{n}=25) \\
\text { Mean } \pm \text { SD }\end{array}$ & $\begin{array}{c}\text { Non-NASH } \\
(\mathrm{n}=25) \\
\text { Mean } \pm \text { SD }\end{array}$ & $\begin{array}{c}\text { P } \\
\text { value }\end{array}$ \\
\hline Age (years) & $41.8 \pm 10.7$ & $39.7 \pm 7.5$ & $0.425 \mathrm{~ns}$ \\
\hline Weight $(\mathrm{kg})$ & $65.6 \pm 8.6$ & $63.3 \pm 9.7$ & $0.444 \mathrm{~ns}$ \\
\hline Height $(\mathrm{cm})$ & $159.2 \pm 9.1$ & $157.7 \pm 8.3$ & $0.545 \mathrm{~ns}$ \\
\hline BMI (kg/m $\left.{ }^{2}\right)$ & $26.0 \pm 3.9$ & $25.5 \pm 4.0$ & $0.656 \mathrm{~ns}$ \\
\hline $\begin{array}{l}\text { Waist circumference } \\
\text { (cm) }\end{array}$ & $97.9 \pm 9.0$ & $93.9 \pm 9.8$ & $0.139 \mathrm{~ns}$ \\
\hline $\begin{array}{l}\text { Systolic blood pressure } \\
\text { (mm of Hg) }\end{array}$ & $129.8 \pm 16.9$ & $128.6 \pm 12.2$ & $0.774 \mathrm{~ns}$ \\
\hline $\begin{array}{l}\text { Diastolic blood } \\
\text { pressure (mm of Hg) }\end{array}$ & $80.2 \pm 7.8$ & $81.0 \pm 6.1$ & $0.688 \mathrm{~ns}$ \\
\hline $\begin{array}{l}\text { Platelet count } \\
\text { (x109/L) }\end{array}$ & $303.1 \pm 68.7$ & $327.8 \pm 66.8$ & $0.203 \mathrm{~ns}$ \\
\hline FBS (mmol/L) & $6.6 \pm 2.8$ & $5.9 \pm 2.2$ & $0.330 \mathrm{~ns}$ \\
\hline 2HABF (mmol/L) & $10.0 \pm 4.2$ & $9.1 \pm 4.7$ & $0.478 \mathrm{~ns}$ \\
\hline Total cholesterol (mg/dl) & $210.0 \pm 48.7$ & $199.9 \pm 38.4$ & $0.419 \mathrm{~ns}$ \\
\hline LDL (mg/dl) & $126.0 \pm 40.5$ & $119.6 \pm 36.7$ & $0.561 \mathrm{~ns}$ \\
\hline HDL (mg/dl) & $40.7 \pm 9.1$ & $36.6 \pm 8.9$ & $0.113 \mathrm{~ns}$ \\
\hline TG (mg/dl) & $209.0 \pm 95.9$ & $222.8 \pm 116.2$ & $0.649 \mathrm{~ns}$ \\
\hline AST (U/L) & $55.2 \pm 30.1$ & $33.6 \pm 20.0$ & $0.004 \mathrm{~s}$ \\
\hline ALT (U/L) & $97.0 \pm 51.5$ & $55.5 \pm 28.6$ & $0.001 \mathrm{~s}$ \\
\hline AST/ALT & $0.6 \pm 0.2$ & $0.7 \pm 0.3$ & $0.171 \mathrm{~ns}$ \\
\hline HOMA-IR & $2.4 \pm 1.9$ & $2.3 \pm 1.6$ & $0.841 \mathrm{~ns}$ \\
\hline GGT (U/L) & $73.6 \pm 48.6$ & $49.9 \pm 25.4$ & $0.035 \mathrm{~s}$ \\
\hline Serum ferritin (uggm/L) & $139.4 \pm 124.5$ & $103.5 \pm 69.9$ & $0.214 \mathrm{~ns}$ \\
\hline
\end{tabular}

In NASH group significantly higher percentage of raised AST had NASH compared with normal AST $(68 \%$ vs.32\%). In Non-NASH group $10 \%$ of elevated AST had no NASH. There was significant difference in the NAFLD activity score for diagnosing NASH between elevated and normal AST (P value 0.004). Higher AST values correlated with higher specificity. By multivariate analysis AST were found to be significant, revealed that AST more than normal have the best possibility of NASH.

\section{AST of the study patients}

Mean AST was found $55.2 \pm 30.1 \mathrm{U} / \mathrm{L}$ in NASH group and $33.6 \pm 20.0 \mathrm{U} / \mathrm{L}$ in Non- NASH group. The mean AST was statistically significant $(\mathrm{p}<0.05)$ between two groups. 
Table-III : Distribution of the study patients according to AST (n=50)

\begin{tabular}{|c|c|c|c|c|c|}
\hline \multirow[t]{2}{*}{$\operatorname{AST}(\mathrm{U} / \mathrm{L})$} & \multicolumn{2}{|c|}{$\begin{array}{c}\text { NASH Group } \\
(\mathrm{n}=25)\end{array}$} & \multicolumn{2}{|c|}{$\begin{array}{c}\text { Non-NASH Group } \\
(\mathrm{n}=25)\end{array}$} & \multirow[t]{2}{*}{$\begin{array}{c}\mathrm{P} \\
\text { value }\end{array}$} \\
\hline & $\mathrm{n}$ & $\%$ & $\mathrm{n}$ & $\%$ & \\
\hline$\leq 37$ & 8 & 32.0 & 20 & 80.0 & \\
\hline $38-100$ & 14 & 56.0 & 4 & 16.0 & \\
\hline$>100$ & 3 & 12.0 & 1 & 4.0 & \\
\hline $\begin{array}{l}\text { Mean } \pm \text { SD } \\
\text { Min-max }\end{array}$ & \multicolumn{2}{|c|}{$\begin{array}{c}55.2 \pm 30.1 \\
20.0-124.0\end{array}$} & \multicolumn{2}{|c|}{$\begin{array}{l}33.6 \pm 20.0 \\
19.0-121.0\end{array}$} & $0.004 \mathrm{~s}$ \\
\hline
\end{tabular}

$S$ = significant

Table-IV: Multivariate logistic regression analysis for association between AST, ALT, AST/ALT, GGT (n=50)

\begin{tabular}{|c|c|c|c|c|c|c|c|}
\hline & \multirow[t]{2}{*}{ B } & \multirow{2}{*}{ S.E } & \multirow{2}{*}{$\mathrm{df}$} & \multirow{2}{*}{ P value } & \multirow[t]{2}{*}{ OR } & \multicolumn{2}{|c|}{$95 \% \mathrm{CI}$ for OR } \\
\hline & & & & & & Lower & Upper \\
\hline AST (U/L) & 1.800 & 1.118 & 1 & $0.018 \mathrm{~s}$ & 6.050 & 0.676 & 54.179 \\
\hline $\operatorname{ALT}(\mathrm{U} / \mathrm{L})$ & 0.285 & 1.025 & 1 & $0.781 \mathrm{~ns}$ & 1.330 & 0.178 & 9.916 \\
\hline AST/ALT ratio & -0.667 & 0.818 & 1 & $0.415 \mathrm{~ns}$ & 0.513 & 0.103 & 2.551 \\
\hline GGT (U/L) & -0.127 & 0.790 & 1 & $0.872 \mathrm{~ns}$ & 0.881 & 0.187 & 4.146 \\
\hline Constant & -0.679 & 0.492 & 1 & 0.167 & 0.507 & & \\
\hline
\end{tabular}

$\mathrm{s}=$ significant, ns=not significant.

A subject with AST $>37$ U/L had 6.05 (95\% CI 0.676 to 54.179) times increase in odds having NASH. AST differences were significantly associated with NASH.

Table-V: Distribution of histological findings in NAFLD patients and AST level (n=50)

\begin{tabular}{|c|c|c|c|c|c|}
\hline & & & \multicolumn{2}{|c|}{ Histological findings( NAS) } & \multirow[t]{2}{*}{ Total } \\
\hline & & & Non-NASH (1-4) & NASH ( 5 or more) & \\
\hline \multirow{4}{*}{ AST level } & \multirow{2}{*}{ Normal $(<37)$} & $\mathrm{n}$ & 20 & 9 & 29 \\
\hline & & $\%$ & $69.0 \%$ & $31.0 \%$ & $100.0 \%$ \\
\hline & \multirow{2}{*}{ High $(>=37)$} & $\mathrm{n}$ & 5 & 16 & 21 \\
\hline & & $\%$ & $23.8 \%$ & $76.2 \%$ & $100.0 \%$ \\
\hline \multirow[t]{2}{*}{ Total } & & $\mathrm{n}$ & 25 & 25 & 50 \\
\hline & & $\%$ & $50.0 \%$ & $50.0 \%$ & $100.0 \%$ \\
\hline
\end{tabular}

NAFLD activity score=NAS, Non-NASH = NAFLD activity score 1-4, NASH= NAFLD activity score 5 or more.

- Pearson correlation between histological findings in NAFLD activity score (NAS) and AST level is 0.365 which is statistically significant $(\mathrm{P}<0.01)$

- $\quad$ Statistics $(95 \% \mathrm{CI})$

Sensitivity $=64.00 \%(42.52 \%$ to $82.03 \%)$

Specificity $=80.00 \%(59.30 \%$ to $93.17 \%)$

Positive Predictive Value $=76.19 \%(58.07 \%$ to $88.08 \%)$

Negative Predictive Value $=68.97 \%$ (55.98\% to $79.52 \%)$

Kappa $=0.440, \mathrm{P}<0.005$ which is statistically significant. 


\section{DISCUSSION}

Non alcoholic fatty liver disease (NAFLD) is a clinico-pathological entity where fat (predominantly triglyceride) accumulates in liver without significant alcohol ingestion or ingestion of certain drugs observed by Adams et al 2009. ${ }^{17}$ It encompasses a spectrum of conditions ranging from simple steatosis to nonalcoholic steatohepatits (NASH), fibrosis and end stage liver disease by Ludwig et al 1980. ${ }^{18}$ Hepatic steatosis is a manifestation of excessive triglyceride accumulation in the liver. The major sources of triglycerides are from fatty acids stored in adipose tissue and fatty acids newly made within the liver through denovo lipogenesis. ${ }^{19}$

Serum ALT level above the ULN (65 U/L) was present in $48 \%$ of NAFLD patients. Mean ALT differed significantly in NASH patients $(97.0 \pm 51.5 \mathrm{U} / \mathrm{L}$ NASH versus $55.5 \pm$ 28.6 U/L in NNFL)(P value- 0.001). But in multivariate analysis serum ALT levels were not significant in NASH patient (P value-0.781, Table-4).Alam et al 2013 showed serum alanine aminotransferase levels were not able to predict NASH. ${ }^{10}$

AST to ALT ratio (AAR) is usually less than 1 in NAFLD patients. ${ }^{2}$ AAR > 1 can be an independent risk factor for advanced fibrosis in NASH according to some studies. ${ }^{6}$ In our study, $92.0 \%$ patients presented with AAR $\leq 1$ having no correlation $(\mathrm{P}=0.171)$ in diagnosing NASH.

The role of GGT, as a marker for disease severity and diagnostics is still obscure in NAFLD. Serum GGT $\geq 30$ $\mathrm{U} / \mathrm{L}$ is an adequate marker of NASH. ${ }^{9}$ Serum GGT level (male 15-85U/L, female 15-55 U/L) above the ULN was $32 \%$ in study population. Only $22 \%$ of NASH population presented with serum GGT above the ULN. Mean GGT was found $73.6 \pm 48.6 \mathrm{U} / \mathrm{L}$ in NASH group and $49.9 \pm 25.4$ $\mathrm{U} / \mathrm{L}$ in Non-NASH group. The mean GGT was statistically significant $(\mathrm{P}=0.035)$ between two group. But in multivariate analysis serum GGT levels were not statistically significant in NASH patient (P value- 0.872 , Table-IV).

Mean AST in NASH group was $55.2 \pm 30.1 \mathrm{U} / \mathrm{L}$, whereas $33.6 \pm 20.0 \mathrm{U} / \mathrm{L}$ in NNFL group. Mean AST differed significantly in NASH patients (P value- 0.004). By multivariate analysis AST were found to be significant(P value- 0.018 , Table-4). AST more than $37 \mathrm{U} / \mathrm{L}$ was present in $23.8 \%$ of NNFL and $76.2 \%$ of NASH patients. AST more than $37 \mathrm{U} / \mathrm{L}$ had a sensitivity of $64 \%$, specificity of $80 \%$, positive predictive value $=76.19 \%$, negative predictive value $=68.97 \%$ for diagnosing NASH. So it revealed that AST more than normal limit have the good possibility of NASH. But Alam et al 2013 showed serum aspartate aminotransferase levels were not able to predict $\mathrm{NASH}^{10}$.

\section{LIMITATION OF THE STUDY}

The present study evaluated predictive values of serum AST and NAFLD activity score(NAS) to distinguish between nonalcoholic steatohepatitis (NASH) and non NASH fatty liver (NNFL) in patients with NAFLD. This study presents some limitations such as small number of patients (50 patient), they were not selected randomly and only selected those patients who attended OPD, so there may be selection bias. All patients were collected in this study from a single tertiary level hospital that may not represent general population of the country. So, current study suffered from lack of multi-centric different ethnic category of patients.

\section{CONCLUSIONS}

Aspartate aminotransferase (AST) level has the good predictive value for diagnosing NASH in NAFLD patients. We therefore propose the use of AST in NAFLD patients for the detection of NASH from Non- NASH.

\section{REFERANCES}

1. Eckel RH, Grundy SM, Zimmet PZ 2005 , The metabolic syndrome, Lancet, vol.365;1415-1428.

2. Adams LA, Talwalkar JA. Diagnostic Evaluation of Nonalcoholic Fatty Liver Disease.J Clin Gastroenterol. 2006; 40: 34-38.

3. Andrea ER. Nonalcoholic Fatty Liver Disease. In: Mark F, Lawrence SF, Lawrence JB, editors. Sleisenger and Fordtran's gastrointestinal and liver disease: pathophysiology/diagnosis/management. 9th ed. Philadelphia: Elsevier; 2010. 1401-13.

4. Pasumarthy L, Srour J, 2010, Nonalcoholic Steatohepatitis: a review of the literature and updates in management. South Med J,vol.103;547-550.

5. Caldwell SH, Al-Osmani AMS, Argo CK. Nonalcoholic fatty liver disease. In: Schiff ER, Maddrey WC, Sorrel MF, editors. Schiff's Disease of the liver.10th ed. Philadelphia.Lippincott Williams \& Wilkins; 2007.1117-681.

6. Angulo P, Keach JC, Batts KP, Lindor KD. Independent predictors of liver fibrosis in patients with nonalcoholic steatohepatitis.Hepatology.1999; 30: 1356-1362. 
7. Angulo P, Hui JM, Marchesini G. The NAFLD fibrosis score: A noninvasive system that identifies liver fibrosis in patients with NAFLD. Hepatology. 2007; 45: 846-854.

8. Annurad E, Shiwaku K, Nogi A, Kitajima K, Enkhmaa B, Shimono K, Yamane Y. The New BMI criteria for Asians by the Regional Office for the Western Pacific Region of WHO are suitable for the screening overweight to prevent metabolic syndrome in Elder Japanese Workers. J occup Health.2003; 45: 335-343.

9. Pulzi FBU, Cisternas RM, Murilo RR, Cristiane MF, Malheiros CA, Salles JE 2011,'New clinical score to diagnose non-alcoholic steatohepatitis in obese patients', Diabetology\& Metabolic Syndrome, vol. 3; 3.

10. Alam S, Alam SMN, Chowdhury ZR, AlamMahbubul , Kabir Jahangir 2013, 'Nonalcoholic steatohepatitis in nonlcoholic liver disease patients of Bangladesh', World J Hepatol,vol.5; 281-287.

11. Argo CK, Northup PG, Al-Osaimi AM, Caldwell SH.Systematic review of risk factors for fibrosis progression in non-alcoholic steatohepatitis. J. Hepatol. 2009; 51: 371-379.

12. Bayard M, Holt J, Boroughs E.Nonalcoholic fatty liver disease. Am Fam Physician. 2006; 73: 1961-1968.

13. .Bellentanis S, Scaglioni F, Marinom, Bedogni G. Epidemiology of non-alcoholic fatty liver disease. Dig Dis. 2010; 28: 155-161.
14. Ioannou GN, Boyko EJ, Lee SP. The prevalence and predictors of elevated serum aminotransferase activity in the United States in 1999-2002. Am J Gastroenterol 2006; 101: 76-82.

15. Fan JG, Saibara T, Chitturi S, Kim BI, Sung JJ, Chutaputti A. What are the risk factors and settings for non-alcoholic fatty liver disease in Asia-Pacific? J Gastroenterol Hepatol 2007; 22: 794-800 .

16. Caldwell SH, Argo CK 2011, .Non-alcoholic Fatty Liver Disease and Nutrition. In: Dooley JS, Lok ASF, Burroughs AK, Heathcote EJ, editors. Sherlock's Diseases of the Liver and Biliary System. 12th ed. West Sussex: Wiley-Blackwell; 2011. 546-67.

17. Adams LA, Waters OR, Knuiman MW, Elliott RR, Olynyk JK, NAFLD as a risk factor for the development of diabetes and the metabolic syndrome: an eleven-year follow-up study, AM J Gastroenterol.2009.Apr.104(4):861-7.

18. Ludwig J, Viggiano TR, McGill DB, Oh BJ 1980, 'Nonalcoholiv steatohepatitis: Mayo Clinic experience with a hitherto unnamed disease', Mayo Clin Proc, vol. 55; 434-438.

19. Bugianesi E, Manzini P, D’AnticoS.Relative contribution of iron burden, HFE mutations, and insulin resistance to fibrosis in nonalcoholic fatty liver. Hepatology. 2004; 39: 179-187. 